\title{
PENILAIAN POSTUR KERJA MANUAL MATERIAL HANDLING (MMH) PADA GEDUNG BERTINGKAT MENGGUNAKAN METODE RAPID UPPER LIMB ASSESSMENT (RULA)
}

\author{
Nur Miswari ${ }^{1)}$, Lina Aulia $\mathbb{i}^{2)}$, dan Rizqi Wahyudi ${ }^{3}{ }^{3)}$ \\ ${ }^{1,2,3}$ Teknik Industri, Jurusan Teknologi Produksi dan Industri, Institut Teknologi Sumatera \\ ${ }_{1,2,3}$ Jl. Terusan Ryacudu, Desa Way Hui, Jati Agung, Lampung Selatan, 35365 \\ E-mail: nur.miswari@ti.itera.ac.id ${ }^{1)}$,lina.aulia@ti.itera.ac.id ${ }^{2)}$, rizky.wahyudi@ti.itera.ac.id ${ }^{3)}$
}

\begin{abstract}
ABSTRAK
Aktivitas penanganan bahan secara manual masih banyak kita temui dalam kehidupan sehari-hari saat melaksanakan sebuah pekerjaan. Ketidak ergonomis pekerjaan manual material handling (MMH) akan menimbulkan risiko keluhan muskuloskeletal disorder (MSDs). Selain dapat menyebabkan risiko-risiko muskuloskeletal, pekerjaan MMH dapat meningkatkan kelelahan otot lokal akibat banyaknya kontraksi otot yang terlibat dan low back pain (LBP). Aktivitas mengangkat dan membawa galon air secara pada gedung bertingkat tentu menjadi tugas yang cukup berat. Penelitian ini dilakukan terhadap aktivitas MMH mengangkat dan membawa air kemasan galon dengan menggunakan metode Rapid Upper Limb Assessment (RULA) untuk menilai postur aktivitas MMH dan mengklasifikasikan dalam tingkatan risiko. Untuk analisis tekanan pada sendi antara lumbal lima dan sacral pertama (L5/S1) dilakukan dengan software prediksi kekuatan dan ketahanan statis tubuh. Hasil yang diperoleh dari penilaian postur dengan metode RULA aktivitas MMH pengangkatan dan membawa galon air mineral secara manual pada gedung bertingkat adalah nilai 7 (tujuh) yang masuk dalam kategori risiko tinggi sehingga perlu adanya perbaikan segera. Hasil analisis gaya tekan L5/S1 pada sikap kerja MMH yaitu sebesar $1644 \mathrm{~N}$ untuk posisi angkat dan $2475 \mathrm{~N}$ saat membawa. Usulan perbaikan yaitu posisi tubuh agar tetap tegak, mengurangi sudut yang terbentuk agar memperkecil momen gaya, menggunakan alat bantu material handling lifting secara mekanis maupun elektrik agar pekerjaan MMH tidak menggunakan kekuatan operator yang berlebihan baik saat mengangkat maupun membawa beban.
\end{abstract}

Kata Kunci: Material Handling, Ergonomi, RULA, Postur, Strength Prediction

\section{PENDAHULUAN}

Ergonomi merupakan ilmu kerja tentang orang-orang yang melakukannya dan bagaimana cara itu dilakukan, alat dan peralatan yang mereka gunakan, tempat mereka bekerja dan aspek psikosial situasi kerja. Maksud dan tujuan disiplin ergonomi adalah mendapatkan pengetahuan yang utuh tentang permasalahanpermasalahan interaksi manusia dengan lingkungan kerja, serta pendekatan multi disiplin ilmu antara manusia dengan pekerjaan, alat pekerjaan, lingkungan pekerjaan serta agar terciptanya ruang dimensi pekerjaan yang efisien, nyaman, aman, sehat, dan efektif.

Salah satu cabang ilmu ergonomi ilmu Biomekanika. Biomekanika merupakan ilmu yang menggunakan hokum fisika dan mekanika teknik untuk dapat menelaah gerakan pada tubuh dan efek dari gaya dan momen yang terjadi. Sehingga beban yang diterima tubuh seseorang dapat diidentifikasi dan diukur agar kekuatan dan keseimbangan serta kemampuan fisik seseorang dalam melaksanakan pekerjaan tetap pada batas yang diizinkan. Pembebanan yang melebihi toleransi dan berulang mengakibatkan ketahanan pada struktur jaringan dapat berkurang dan mengakibatkan cedera atau penyakit. Oleh karena itu tata cara dan peralatan harus dirancang menyesuaikan kemampuan tubuh manusia saat beraktivitas (Wijaya \& Muhsin, 2018).

Diantara kajian biomekanika aktivitas penanganan material secara manual atau manual material handling (MMH) merupakan suatu hal yang masih dianggap kritis. Meskipun semakin berkembangnya industri modern yang telah mengaplikasikan mesin atau peralatan dalam memudahkan pekerjaan penanganan material, namun masih terdapat beberapa kriteria pekerjaan yang harus dilakukan dengan secara manual mengandalkan kekuatan fisik manusia, keterbatasan ruang gerak, maupun akselerasi pekerja (Affa \& Putra, 2017)

Aktivitas MMH yang sering ditemui adalah pekerjaan mengangkat (lifting) dan membawa (carrying). Aktivitas penanganan bahan secara manual atau manual material handling (MMH) masih banyak kita temui dalam kehidupan sehari-hari saat melaksanakan sebuah pekerjaan. Salah satu aktivitas MMH adalah mengangkat dan membawa air minum dalam kemasan galon. Namun perlu digaris bawahi, aktivitas MMH pada kondisi dan cara yang tidak tepat akan menimbulkan sejumlah dampak pada aktivitas tersebut seperti tingginya tingkat 
cedera atau kecelakaan dapat menyebabkan sakit atau keluhan pada pekerja / operator (Sanjaya et al., 2018), kecelakaan kerja, penyakit akibat kerja, keluhan muskuloskeletal, risiko cedera tulang punggung belakang atau low back paint (LBP) dan kelelahan (Zen \& Zamora, 2016). Beberapa penelitian (Taofik \& Mauluddin, 2015) (Susihono, 2016) (Oesman et al., 2019) (Zen \& Zamora, 2016) terkait manual material handling memberikan usulan-usulan perbaikan baik metode maupun fasilitas dan peralatan kerja.

Postur kerja seseorang dalam melakukan pekerjaan ini memiliki peran penting terhadap penyebab faktor risiko ergonomi. Hal ini mengakibatkan konsekuensi terhadap rendahnya produktivitas, kualitas, keamanan dan kesehatan, dan masalah serius lainnya. Hal ini dikarenakan kondisi beban atau galon yang di angkat merupakan sebuah beban yang cukup besar dan berat dengan kondisi coupling atau pegangan yang tidak simetris. Dengan bentuk, kondisi beban tersebut, tugas melaksanakan $\mathrm{MMH}$ dengan cara menaiki tangga pada lokasi gedung yang bertingkat, dengan postur yang canggung akan berkontribusi terhadap gangguan MSDs (muskulo skeletal disorder).

National Institute of Occupational Safety and Health menemukan metode NIOSH yang menganalisis postur berdasarkan gaya kompresi yang dihasilkan dan merekomendasikan beban yang aman untuk dikerjakan. Kemudian pada tahun 1995 muncul metode Rapid Entire Body Assesment (REBA) dan Rapid Upper Limb Assessment (RULA) pada tahun 1993. Penggunaan metode penilaian postur Rapid Upper Limb Assessment (RULA) merupakan metode yang dikembangkan oleh McAtamney \& Nigel Corlett (Namwongsa et al., 2018) yang menginvestasikan dan menilai posisi kerja yang dilakukan oleh tubuh ekstremitas atas. (Bintang \& Dewi, 2017). Metode RULA dapat menjadi sebuah tools yang dapat menilai serta memberikan evaluasi metode kerja berdasarkan postur saat aktivitas dilakukan berdasarkan klasifikasi action level. (Tiogana \& Hartono, 2020) dan (Sunedi et al., 2019) dalam penelitiannya, hasil penilaian RULA dengan nilai 6 memberikan rekomendasi perancangan peralatan bantu dan perbaikan metode kerja (Bintang, 2017).

\section{RUANG LINGKUP} berikut:

Ruang lingkup dalam penelitian ini adalah sebagai

1. Cakupan permasalahan yang dilakukan dalam penelitian ini yaitu menilai postur suatu aktivitas manual material handling yang selama ini dikerjakan pada gedung bertingkat.

2. Batasan dalam penelitian ini hanya dilakukan analisis postur secara 3 dimensi statis. Beban aktivitas pengangkatan dan membawa galon air minum adalah $19 \mathrm{Kg}$, beban yang lainnya baik akibat yang ditimbulkan dari aktivitas $\mathrm{MMH}$ maupun beban internal dari pekerja / operator di asumsi tidak ada dan dianggap tidak mempengaruhi postur dan beban eksternal atau objek yang diangkat.

3. Faktor-faktor individual seperti usia, daya tahan atau kebugaran, dan kebiasaan beraktivitas $\mathrm{MMH}$ dianggap tidak mempengaruhi hasil penilaian.

\section{BAHAN DAN METODE}

Jenis penelitian observational analytic menggunakan deskriptif kualitatif. Metode yang digunakan dalam pengumpulan data adalah metode observasi. Metode observasi adalah teknik pengumpulan data yang dilakukan melalui suatu pengamatan pada suatu objek. Alat yang digunakan saat pengambilan data dalam penelitian ini meliputi alat tulis, kamera, dan worksheet RULA dan perangkat lunak perhitungan matematis prediksi beban kompresi dan animasi postur dari berbagai sisi pandang. Observasi dilakukan dengan mengamati dan mengambil dokumentasi postur kerja operator dari sumbu sagittal saat mengangkat dan membawa beban dari lantai dasar hingga lantai empat. Pengolahan menggunakan 3 Dimension Static Strength Prediction Program (3DSSPP) digunakan untuk mendapatkan gambaran detail postur dan mengetahui beban atau gaya di L5/S1. Citra postur kemudian dilakukan pengukuran sudut pada setiap joint data postur kemudian dianalisis dengan metode Rapid Upper Limb Assessment (RULA) untuk menganalisa postur tubuh pekerja dan mengetahui apakah pekerjaan tersebut ada risiko atau tidak. Berdasarkan (Taofik \& Mauluddin, 2015) metode RULA dibagi dalam 2 grup, yaitu Grup A dan Grup B.

\subsection{Grup A}

Pada bagian grup A, penilaian dilakukan dengan memberikan skor terhadap segment tubuh yang melakukan gerakan sehingga membentuk sudut. Adapun segment-segment pada grup A terdiri dari

1. Lengan atas (upper arm),

2. Lengan bawah (lower arm),

3. Pergelangan (wrist), dan

4. Putaran telapak tangan (wrist twist).

Nilai setiap segment pada grup A dimasukkan ke dalam tabel Grup A seperti pada Tabel 1. 
Tabel 1. Nilai Postur Tubuh Grup A

\begin{tabular}{|c|c|c|c|c|c|c|c|c|c|}
\hline \multirow{4}{*}{ UA } & \multirow{4}{*}{ LA } & \multicolumn{8}{|c|}{ W } \\
\hline & & \multicolumn{2}{|c|}{1} & \multicolumn{2}{|c|}{2} & \multicolumn{2}{|c|}{3} & \multicolumn{2}{|c|}{4} \\
\hline & & \multicolumn{2}{|c|}{ WT } & \multicolumn{2}{|c|}{ WT } & \multicolumn{2}{|c|}{ WT } & \multicolumn{2}{|c|}{ WT } \\
\hline & & 1 & 2 & 1 & 2 & 1 & 2 & 1 & 2 \\
\hline \multirow{3}{*}{1} & 1 & 1 & 2 & 2 & 2 & 2 & 3 & 3 & 3 \\
\hline & 2 & 2 & 2 & 2 & 2 & 3 & 3 & 3 & 3 \\
\hline & 3 & 2 & 3 & 2 & 3 & 3 & 3 & 4 & 4 \\
\hline \multirow{3}{*}{2} & 1 & 2 & 2 & 2 & 3 & 3 & 3 & 4 & 4 \\
\hline & 2 & 2 & 2 & 2 & 3 & 3 & 3 & 4 & 4 \\
\hline & 3 & 2 & 3 & 3 & 3 & 3 & 4 & 4 & 5 \\
\hline \multirow{3}{*}{3} & 1 & 2 & 3 & 3 & 3 & 4 & 4 & 5 & 5 \\
\hline & 2 & 2 & 3 & 3 & 3 & 4 & 4 & 5 & 5 \\
\hline & 3 & 2 & 3 & 3 & 4 & 4 & 4 & 5 & 5 \\
\hline \multirow{3}{*}{4} & 1 & 3 & 4 & 4 & 4 & 4 & 4 & 5 & 5 \\
\hline & 2 & 3 & 4 & 4 & 4 & 4 & 4 & 5 & 5 \\
\hline & 3 & 3 & 4 & 4 & 5 & 5 & 5 & 6 & 6 \\
\hline \multirow{3}{*}{5} & 1 & 5 & 5 & 5 & 5 & 5 & 6 & 6 & 7 \\
\hline & 2 & 5 & 6 & 6 & 6 & 6 & 7 & 7 & 7 \\
\hline & 3 & 6 & 6 & 6 & 7 & 7 & 7 & 7 & 8 \\
\hline \multirow{3}{*}{6} & 1 & 7 & 7 & 7 & 7 & 7 & 8 & 8 & 9 \\
\hline & 2 & 7 & 8 & 8 & 8 & 8 & 9 & 9 & 9 \\
\hline & 3 & 9 & 9 & 9 & 9 & 9 & 9 & 9 & 9 \\
\hline
\end{tabular}

Dimana UA (upper arm) penilaian ditinjau dari sudut yang terbentuk dari segment lengan atas terhadap sumbu vertikal (sumbu Y). Adapun penilaian pada segmen lengan atas (UA) dapat dilihat seperti pada Tabel 2.

Tabel 2. Pedoman Penilaian Segmen Lengan Atas

\begin{tabular}{|c|c|c|c|}
\hline No. & Kategori Postur & Skor & Gambar \\
\hline 1 & Membentuk sudut $20^{\circ}$ & 1 & \\
\hline 2 & $\begin{array}{c}\text { Membentuk sudut } 21^{0} \\
\text { sampai } 45^{0}\end{array}$ & 2 & \\
\hline 3 & $\begin{array}{c}\text { Membentuk sudut } 46^{0} \\
\text { sampai } 90^{\circ}\end{array}$ & 3 & \\
\hline 4 & membentuk sudut $>90^{\circ}$ & 4 & \\
\hline & & & +4 \\
\hline
\end{tabular}

LA (lower arm) penilaian ditinjau dari sudut yang terbentuk dari segment lengan bawah terhadap sumbu vertikal (sumbu Y). Adapun penilaian pada segmen lengan bawah (LA) dapat dilihat seperti pada Tabel 3
Tabel 3. Pedoman Penilaian Segmen Lengan Bawah

\begin{tabular}{|c|c|c|c|}
\hline No. & Kategori Postur & Skor & Gambar \\
\hline 1 & $\begin{array}{c}\text { Membentuk sudut } \\
60^{\circ}-100^{\circ}\end{array}$ & 1 \\
\hline 2 & $\begin{array}{c}\text { Membentuk sudut } \\
<60^{\circ} \text { atau }>100^{\circ}\end{array}$ & 2 & \\
\hline 3 & Posisi menyilang & 3 & \\
\hline
\end{tabular}

W (wrist) penilaian ditinjau dari sudut yang terbentuk dari segmen pergelangan tangan terhadap arah lengan bawah. Adapun penilaian pada segmen pergelangan tangan (W) dapat dilihat seperti pada Tabel 4.

Tabel. Pedoman Penilaian Segmen Pergelangan Tangan

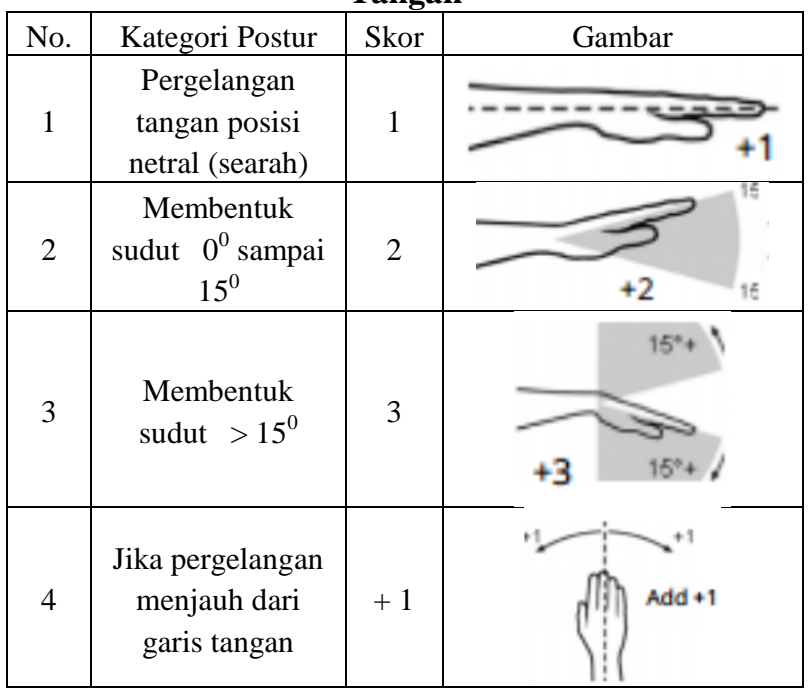

WT (wrist twist) penilaian ditinjau dari posisi segment telapak yang tertekuk pada segmen putaran pergelangan tangan (WT). Adapun penilaian pada putaran pergelangan tangan (WT) dapat dilihat seperti pada Tabel 5 
Tabel 5. Pedoman Penilaian Putaran Tangan

\begin{tabular}{|c|c|c|c|}
\hline No. & Kategori Postur & Skor & Gambar \\
\hline 1 & $\begin{array}{c}\text { Putaran telapak tangan } \\
\text { berada pada posisi } \\
\text { tengah }\end{array}$ & 1 & \\
\hline 2 & $\begin{array}{c}\text { Telapak tangan terlekuk } \\
\text { di dekat atau di akhir } \\
\text { dari putaran }\end{array}$ & 2 & \\
\hline
\end{tabular}

Setelah menilai segmen pada grup A, skor hasil di tambahkan faktor nilai aktivitas dan nilai beban dimana setiap aktivitas bersifat statis dan aktivitas dilakukan pengulangan maka skor masing-masing ditambahkan nilai 1. Untuk nilai beban penambahan skor akan bertambah jika beban eksternal yang diangkut melebihi $2 \mathrm{Kg}$. Adapun tabel penambahan skor terhadap nilai aktivitas dan nilai beban ditunjukkan pada Tabel 6 .

Tabel 6. Penambahan Nilai Aktivitas

\begin{tabular}{|l|c|l|}
\hline \multicolumn{1}{|c|}{ Aktivitas } & Skor & \multicolumn{1}{|c|}{ Keterangan } \\
\hline Postur statik & +1 & Satu atau lebih bagian tubuh statis \\
\hline Pengulangan & +1 & $\begin{array}{l}\text { Tindakan dilakukan berulang lebih } \\
\text { dari 4 kali per menit }\end{array}$ \\
\hline$<2 \mathrm{Kg}$ & 0 & - \\
\hline $2 \mathrm{Kg}-10 \mathrm{Kg}$ & 1 & $\begin{array}{l}+1 \text { jika postur statis dan dilakukan } \\
\text { secara berulang-ulang }\end{array}$ \\
\hline$>10 \mathrm{Kg}$ & 3 & - \\
\hline
\end{tabular}

\subsection{Grup B}

Pada grup B, penilaian juga dilakukan dengan memberikan skor terhadap segment tubuh yang melakukan gerakan sehingga membentuk sudut tertentu. Adapun segmen-segmen pada grup B terdiri dari

1. leher (neck),

2. Punggung (trunk), dan

3. Kaki (legs),

Nilai setiap segment pada grup B dimasukkan ke dalam tabel Grup B seperti pada Tabel 7.

Tabel 7. Skor RULA Grup B

\begin{tabular}{|c|c|c|c|c|c|c|c|c|c|c|c|c|}
\hline \multirow{4}{*}{$\mathrm{N}$} & \multicolumn{12}{|c|}{$\mathrm{T}$} \\
\hline & \multicolumn{2}{|c|}{1} & \multicolumn{2}{|c|}{2} & \multicolumn{2}{|c|}{3} & \multicolumn{2}{|c|}{4} & \multicolumn{2}{|c|}{5} & \multicolumn{2}{|c|}{6} \\
\hline & \multicolumn{2}{|c|}{$\mathrm{L}$} & \multicolumn{2}{|c|}{$\mathrm{L}$} & \multicolumn{2}{|c|}{$\mathrm{L}$} & \multicolumn{2}{|c|}{$\mathrm{L}$} & \multicolumn{2}{|c|}{$\mathrm{L}$} & \multicolumn{2}{|c|}{$\mathrm{L}$} \\
\hline & 1 & 2 & 1 & 2 & 1 & 2 & 1 & 2 & 1 & 2 & 1 & 2 \\
\hline 1 & 1 & 3 & 2 & 3 & 3 & 4 & 5 & 5 & 6 & 6 & 7 & 7 \\
\hline 2 & 2 & 3 & 2 & 3 & 4 & 5 & 5 & 5 & 6 & 7 & 7 & 7 \\
\hline 3 & 3 & 3 & 3 & 4 & 4 & 5 & 5 & 6 & 6 & 7 & 7 & 7 \\
\hline 4 & 5 & 5 & 5 & 6 & 6 & 7 & 7 & 7 & 7 & 7 & 8 & 8 \\
\hline 5 & 7 & 7 & 7 & 7 & 7 & 8 & 8 & 8 & 8 & 8 & 8 & 8 \\
\hline 6 & 8 & 8 & 8 & 8 & 8 & 8 & 8 & 9 & 9 & 9 & 9 & 9 \\
\hline
\end{tabular}

Dimana N (neck) penilaian ditinjau dari sudut yang terbentuk dari segment leher terhadap sumbu vertikal (sumbu Y). Adapun penilaian pada leher (N) dapat dilihat seperti pada Tabel 8

Tabel 8. Pedoman Penilaian Segmen Leher

\begin{tabular}{|c|c|c|c|}
\hline No. & Kategori Postur & Skor \\
\hline 1 & $\begin{array}{c}\text { Jika posisi leher } \\
\text { membentuk sudut 00-100 }\end{array}$ & 1 \\
2 & $\begin{array}{c}\text { Jika posisi leher } \\
\text { membentuk sudut 100-200 }\end{array}$ & 2 & Gambar \\
\hline 3 & $\begin{array}{c}\text { Jika posisi leher } \\
\text { membentuk sudut }>200\end{array}$ & 3 & $\begin{array}{c}\text { Jika leher selalu mengadah } \\
\text { ke atas atau terlalu } \\
\text { menekuk ke bawah }\end{array}$ \\
\hline 4 & 4 & \\
\hline
\end{tabular}

Jika leher operator membentuk sudut terhadap sumbu horizontal atau terlekuk ke samping (kiri/kanan) maka nilai akan ditambah skor nilai 1 dan jika leher ikut memutar ditambahkan nilai 1 .

$\mathrm{T}$ (trunk) penilaian ditinjau dari sudut yang terbentuk pada tulang punggung saat melakukan aktivitas terhadap sumbu vertikal (sumbu Y). Adapun penilaian pada segmen Punggung ( $\mathrm{T}$ ) dapat dilihat seperti pada Tabel 9 
Tabel 9. Pedoman Penilaian Segmen Punggung

\begin{tabular}{|c|c|c|c|}
\hline No. & Kategori Postur & Skor & Gambar \\
\hline 1 & $\begin{array}{c}\text { Jika pekerja / operator } \\
\text { pada posisi duduk } \\
\text { atau punggung } \\
\text { ditopang oleh pinggul } \\
\text { atau tegak dengan } \\
\text { sudut } 0^{0} \text { terhadap } \\
\text { sumbu Y }\end{array}$ & 1 & \\
\hline 2 & $\begin{array}{c}\text { Jika membentuk sudut } \\
0^{0} \text { sampai } 20^{0} \text { terhadap } \\
\text { sumbu Y }\end{array}$ & 2 & \\
\hline 3 & $\begin{array}{c}\text { Jika punggung } \\
\text { membentuk sudut } 20^{0} \\
\text { sampai } 60^{\circ} \text { terhadap } \\
\text { sumbu Y }\end{array}$ & 3 & \\
\hline 4 & $\begin{array}{c}\text { Jika punggung } \\
\text { membentuk sudut }> \\
60^{\circ} \text { terhadap sumbu Y }\end{array}$ & 4 & \\
\hline
\end{tabular}

Jika punggung operator membentuk sudut terhadap sumbu horizontal atau terlekuk ke samping (kiri/kanan) maka nilai akan ditambah skor nilai 1 dan jika punggung ikut memutar ditambahkan nilai 1 .

Sedangkan L (legs) penilaian ditinjau dari distribusi beban pada kaki dengan kondisi yang menapak pada lantai.

1. Jika paha dan kaki disangga dengan baik pada saat duduk dan tubuh selalu dalam keadaan seimbang, nilai $=1$

2. Jika dalam posisi berdiri dimana berat tubuh didistribusikan merata pada kedua kaki, nilai $=2$

Hasil pada penilaian pada grup B selanjutnya ditambahkan dengan faktor nilai aktivitas dan nilai beban pada Tabel 2 sama halnya seperti penilaian pada grup A. Dari hasil kedua skor penilaian didapatkan kemudian skor grup A dan grup B dikombinasikan kedalam penilaian akhir seperti Tabel 10.
Tabel 10. Penilaian akhir RULA

\begin{tabular}{|c|c|c|c|c|c|c|c|}
\hline \multirow{2}{*}{ Nilai grup A } & \multicolumn{7}{|c|}{ Nilai grup B } \\
\cline { 2 - 8 } & 1 & 2 & 3 & 4 & 5 & 6 & $7+$ \\
\hline 1 & 1 & 2 & 3 & 3 & 4 & 5 & 5 \\
\hline 2 & 2 & 2 & 3 & 4 & 4 & 5 & 5 \\
\hline 3 & 3 & 3 & 3 & 4 & 5 & 6 & 6 \\
\hline 4 & 3 & 3 & 3 & 4 & 5 & 6 & 6 \\
\hline 5 & 4 & 4 & 4 & 5 & 6 & 7 & 7 \\
\hline 6 & 4 & 4 & 5 & 6 & 6 & 7 & 7 \\
\hline 7 & 5 & 5 & 6 & 6 & 7 & 7 & 7 \\
\hline $8+$ & 5 & 5 & 6 & 7 & 7 & 7 & 7 \\
\hline
\end{tabular}

Adapun skor penilaian akhir pada RULA ini diklasifikasikan pada action level sebagai acuan rekomendasi perbaikan seperti pada Tabel 11.

Tabel 11. Action level Metode RULA

\begin{tabular}{|c|l|l|}
\hline Nilai & \multicolumn{1}{|c|}{ Kategori } & \multicolumn{1}{|c|}{ Aksi } \\
\hline $1-2$ & 1 (aman) & Bisa diterima \\
\hline $3-4$ & 2 (kecil) & $\begin{array}{l}\text { Perlu tindakan beberapa waktu } \\
\text { ke depan }\end{array}$ \\
\hline $5-6$ & 3 (sedang) & $\begin{array}{l}\text { Pemeriksaan dan perubahan } \\
\text { waktu dekat }\end{array}$ \\
\hline 7 & 4 (tinggi) & Tindakan sekarang juga \\
\hline
\end{tabular}

\section{PEMBAHASAN}

Analisis postur dari 2 (dua) aktivitas MMH yaitu postur saat mengangkat dan postur saat membawa dibahas pada bagian ini. Tangkapan gambar postur kerja pada aktivitas $\mathrm{MMH}$ pengangkatan dan membawa galon air mineral dapat dilihat seperti pada Gambar 1 dan Gambar 2. Adapun sudut yang terbentuk pada segmen tubuh aktivitas MMH disajikan pada Tabel 12 dan Tabel 13 sedangkan analisis penilaian postur aktivitas mengangkat dan membawa dijelaskan lebih detail pada sub bagian selanjutnya.

Tabel 12. Posisi Saat Aktivitas Mengangkat

\begin{tabular}{|c|c|c|}
\hline Segment & Posisi & skor \\
\hline LA & $<60^{0}$ & 1 \\
\hline UA & $0-20^{0}$ & 2 \\
\hline $\mathrm{W}$ & $>15^{0}$ & 3 \\
\hline $\mathrm{WT}$ & Memutar & 2 \\
\hline $\mathrm{N}$ & $>20^{0}$ & 3 \\
\hline $\mathrm{T}$ & $0-20^{0}$ & 2 \\
\hline $\mathrm{L}$ & $\begin{array}{c}\text { Posisi berdiri } \\
\text { tubuh seimbang }\end{array}$ & 2 \\
\hline Nilai Aktivitas & - & 0 \\
\hline Nilai Beban & $>10 \mathrm{Kg}$ & 3 \\
\hline
\end{tabular}


Tabel 13. Posisi Saat Melakukan Aktivitas Membawa

\begin{tabular}{|c|c|c|}
\hline Segment & Posisi & skor \\
\hline LA & $<60^{\circ}$ & 1 \\
\hline UA & $0-20^{0}$ & 1 \\
\hline $\mathrm{W}$ & Searah / netral & 1 \\
\hline WT & Memutar & 1 \\
\hline $\mathrm{N}$ & $0-10^{0}$ & 1 \\
\hline $\mathrm{T}$ & $0-20^{0}$ & 2 \\
\hline $\mathrm{L}$ & $\begin{array}{c}\text { Posisi berdiri } \\
\text { tubuh seimbang }\end{array}$ & 2 \\
\hline Nilai Aktivitas & $\begin{array}{c}1 \text { atau lebih } \\
\text { segment statis }\end{array}$ & 1 \\
\hline Nilai Beban & $>10 \mathrm{Kg}$ & 3 \\
\hline
\end{tabular}

\subsection{Aktivitas Mengangkat Beban}

Penilaian postur aktivitas mengangkat pada segmen grup A dapat kita lihat posisi lengan atas membentuk sudut $14^{0}$ yang terbentuk dari posisi lengan atas dengan garis vertical seperti yang terlihat pada Gambar 1, sehingga skor untuk segmen lengan atas adalah 1. Untuk segmen lengan bawah yang membentuk postur $<60^{\circ}$ sehingga skor untuk lengan atas adalah 2. Pada Gambar 1 posisi segmen pergelangan tangan membentuk sudut $22^{0}$ pada. dari lengan bawah sehingga untuk skor telapak tangan adalah 3. Pergelangan / posisi segmen putaran pergelangan pada salah satu tangan memuntir sehingga skor untuk telapak tangan adalah 1 . Posisi telapak tangan memuntir/memutar dilakukan untuk menjaga keseimbangan bagian atas beban dikarenakan bentuk beban yang tidak simetris.

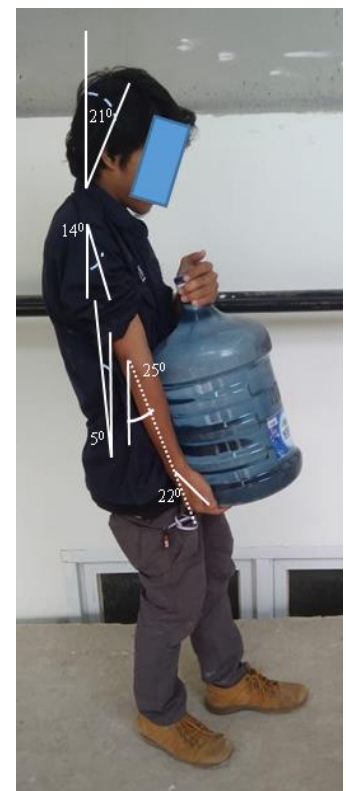

Gambar 1. Postur aktivitas mengangkat

Dari skor yang telah ditinjau sudut yang terbentuk pada setiap segmen pada grup A dimasukkan kedalam Tabel 1, maka didapat skor postur grup $\mathrm{A}=3$. Penilaian grup A ditambahkan nilai beban, aktivitas MMH dengan beban galon $>10 \mathrm{Kg}$ maka skor ditambahkan 3. Total skor pada grup $\mathrm{A}=3+3=6$

Untuk penilaian skor grup B aktivitas mengangkat beban pada Gambar.1 dapat kita lihat postur leher membentuk sudut $21^{0}$ sehingga skor segmen leher adalah 3. Untuk segmen punggung, postur membentuk sudut $5^{0}$ dengan skor nilai 2. Pada bagian segmen kaki, dapat dilihat posisi yang menapak kedua belah kaki dengan distribusi beban yang seimbang sehingga skor segmen kaki adalah 2. Dari skor penilaian masing-masing segmen pada grup B dimasukkan kedalam Tabel 7, maka didapat skor postur grup $B=4$. Seperti halnya grup A, skor grup B ditambahkan dengan skor nilai nilai beban. Sehingga total skor pada Grup B adalah $4+3=7$.

Untuk skor akhir, masing-masing skor pada grup A dan $\mathrm{B}$ aktivitas mengangkat beban dimasukkan kedalam Tabel 10 sehingga skor RULA aktivitas MMH menjadi 7 seperti yang ditunjukkan garis merah pada Tabel 13. Dari hasil ini dapat kita lihat berdasarkan Tabel 11, aktivitas mengangkat termasuk dalam klasifikasi untuk tindakan segera. Adapun postur body segment mengangkat dapat dilihat dari berbagai sisi seperti pada Gambar.2. Sedangkan analisis beban tulang belakang aktivitas MMH mengangkat galon di replika dengan menggunakan software 3DSSPP trial version yang dikembangkan oleh University of Michigan seperti pada Gambar 3. Berdasarkan Gambar 3 menunjukkan bahwa gaya kompresi pada sendi antara otot lumbal kelima dan sacral pertama (L5/S1) senilai 1644N masih cukup aman dibawah ambang batas $3400 \mathrm{~N}$ yang disarankan National Institute of Occupational Safety and Health (NIOSH) (Afshari et al., 2018) . Hal ini dapat dipengaruhi oleh pusat gravitasi beban cukup dekat dengan posisi titik joint L5/S1 sehingga lengan momen menjadi kecil yaitu $33,4 \mathrm{~cm}$ dengan beban $566 \mathrm{~N}$ dimana semakin dekat posisi beban maka kecil jarak lengan beban yang berdampak semakin kecil gaya yang dihasilkan.

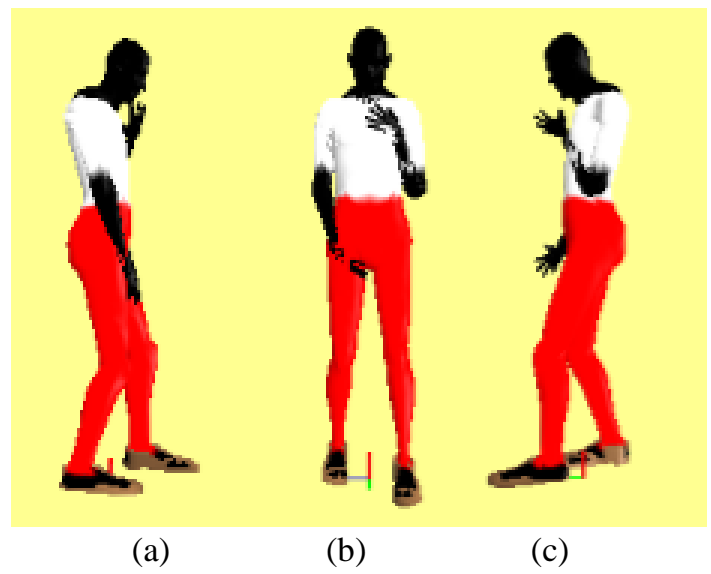

Gambar 2. Postur Mengangkat dari Berbagai Sisi (a) Sisi Kanan (b) Sisi Depan (c) Sisi Kiri 


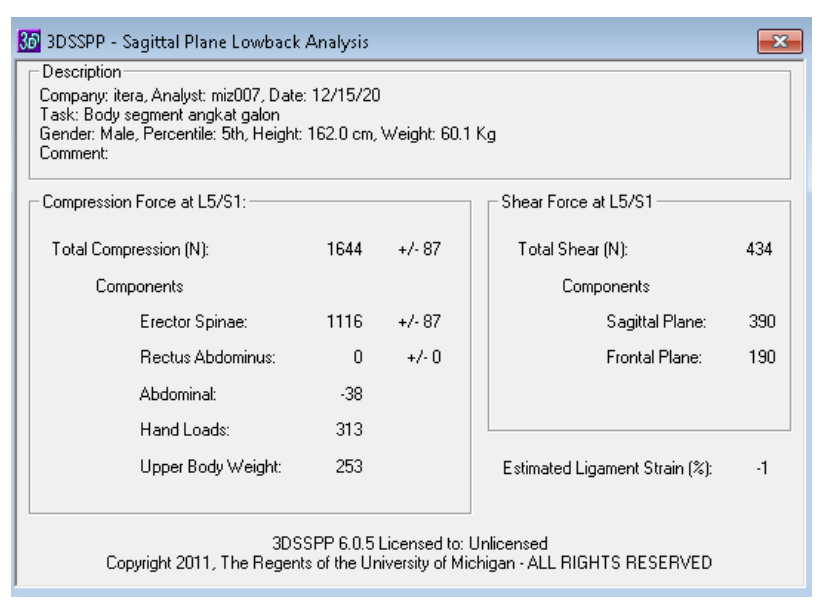

Gambar 6. Analisis Gaya Kompresi Pada Tulang Belakang Aktivitas Mengangkat

\subsection{Aktivitas Membawa Beban}

Seperti halnya penilaian aktivitas mengangkat, penilaian aktivitas membawa dapat dinilai berdasarkan tangkapan gambar operator melakukan aktivitas. penilaian aktivitas membawa beban dapat dilihat seperti pada Gambar.4 dimana postur yang terbentuk cenderung lurus atau tegak. Skor pada segmen grup A berdasarkan Gambar 4 dapat kita lihat untuk posisi lengan atas membentuk sudut $5^{0}$ sehingga skor untuk segmen lengan atas adalah 1. Untuk segmen lengan bawah yang membentuk postur $55^{0}$ seperti yang terlihat pada Gambar.4 sehingga skor untuk lengan atas adalah 1 . Pada posisi segmen pergelangan tangan membentuk sudut searah dengan lengan bawah sehingga untuk skor telapak tangan adalah 1. Pergelangan / posisi segmen putaran telapak tangan pada salah satu tangan memuntir namun masih pada posisi di tengah sehingga skor untuk telapak tangan adalah 1. Posisi telapak tangan memuntir/memutar dilakukan untuk menjaga keseimbangan bagian atas beban dikarenakan bentuk beban yang tidak simetris.

Dari skor yang telah ditinjau sudut yang terbentuk pada setiap segmen pada grup A dimasukkan kedalam Tabel 1, maka didapat skor postur grup $A=2$. Penilaian grup A ditambahkan dengan skor nilai aktivitas dimana pada saat aktivitas $\mathrm{MMH}$, lengan atas, lengan bawah dan pergelangan tangan dalam keadaan statis sehingga skor ditambahkan 1. Untuk nilai beban, aktivitas MMH dengan beban galon $>10 \mathrm{Kg}$ maka skor ditambahkan 3 . Total skor pada grup $\mathrm{A}=1+1+3=5$

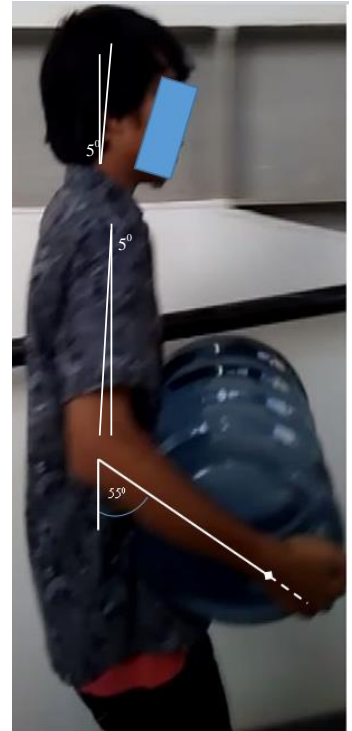

Gambar 4. Postur Aktivitas Membawa

Untuk penilaian skor grup B aktivitas membawa beban, berdasarkan Gambar.4 postur leher membentuk sudut $5^{0}$ sehingga skor segmen leher adalah 1 . Untuk segmen punggung, postur membentuk sudut $5^{0}$ dengan skor nilai 2. Pada bagian segmen kaki, dapat dilihat posisi yang menapak kedua belah kaki dengan distribusi beban yang seimbang sehingga skor segmen kaki adalah 2. Dari skor penilaian masing-masing segmen pada grup B dimasukkan kedalam Tabel 7, maka didapat skor postur grup $B=4$. Seperti halnya grup A, skor grup B ditambahkan dengan skor nilai aktivitas dan nilai beban. Sehingga total skor pada Grup B adalah $3+1+3=7$.

Untuk skor akhir, masing-masing skor pada grup A dan $\mathrm{B}$ aktivitas membawa beban dimasukkan kedalam Tabel 10 sehingga skor RULA aktivitas MMH menjadi 7 seperti yang ditunjukkan pada Tabel 13. Dari hasil ini dapat kita lihat berdasarkan Tabel 11, aktivitas mengangkat termasuk dalam klasifikasi untuk tindakan segera. Adapun postur body segment mengangkat dapat dilihat dari berbagai sisi seperti pada Gambar.5 Sedangkan analisis beban tulang belakang aktivitas MMH membawa galon seperti pada Gambar.6 menunjukkan bahwa gaya kompresi pada L5/S1 senilai $2580 \mathrm{~N}$ masih cukup aman dibawah ambang batas $3400 \mathrm{~N}$ yang disarankan National Institute of Occupational Safety and Health (NIOSH). 


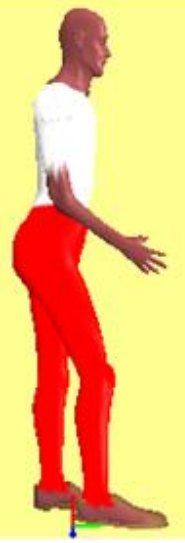

(a)

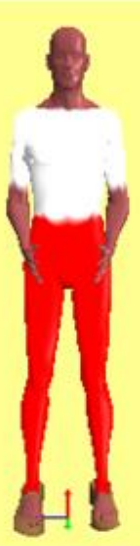

(b)

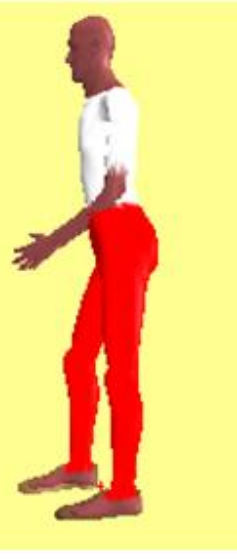

(c)
Gambar 5. Postur Membawa Dari Berbagai Sisi (a) Sisi Kanan (b) Sisi Depan (c) Sisi Kiri

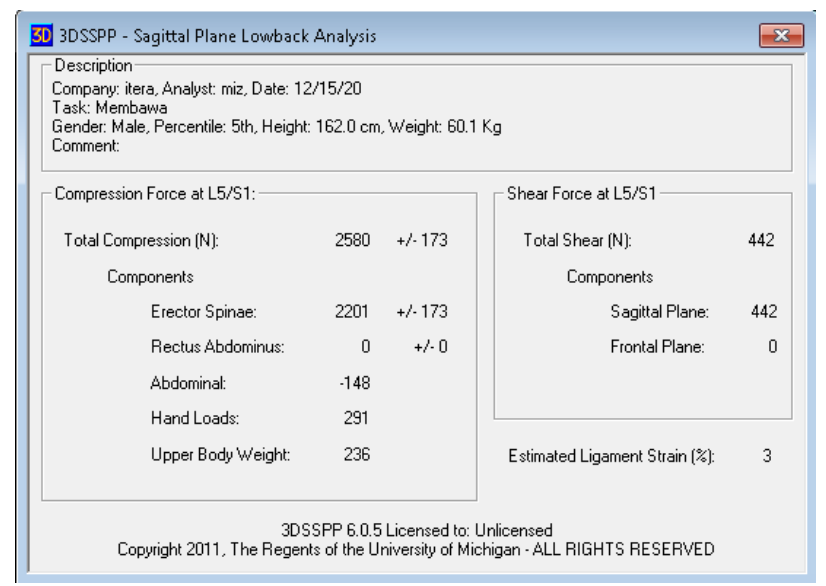

Gambar 6. Analisis Gaya Kompresi Pada Tulang Belakang Aktivitas Membawa

Tabel 13. Penilaian Akhir RULA Aktivitas MMH

\begin{tabular}{|c|c|c|c|c|c|c|c|}
\hline \multirow{2}{*}{$\begin{array}{c}\text { Nilai grup } \\
\text { A }\end{array}$} & \multicolumn{7}{|c|}{ Nilai grup B } \\
\cline { 2 - 9 } & 1 & 2 & 3 & 4 & 5 & 6 & \multicolumn{2}{|c|}{$7+$} \\
\hline 1 & 1 & 2 & 3 & 3 & 4 & 5 & 5 \\
\hline 2 & 2 & 2 & 3 & 4 & 4 & 5 & 5 \\
\hline 3 & 3 & 3 & 3 & 4 & 5 & 6 & 6 \\
\hline 4 & 3 & 3 & 3 & 4 & 5 & 6 & 6 \\
\hline 5 & 4 & 4 & 4 & 5 & 6 & 7 & 7 \\
\hline 6 & 4 & 4 & 5 & 6 & 6 & 7 & 7 \\
\hline 7 & 5 & 5 & 6 & 6 & 7 & 7 & 7 \\
\hline $8+$ & 5 & 5 & 6 & 7 & 7 & 7 & 7 \\
\hline
\end{tabular}

Dari hasil penilaian postur kerja pada aktivitas manual material handling air mineral kemasan galon dengan beban $19 \mathrm{Kg}$, baik saat mengangkat dan membawa beban dengan skor nilai 7 (tujuh), berdasarkan action level pada Tabel 11 termasuk dalam kategori sangat tinggi dimana penilaian berada pada klasifikasi action tindakan segera sehingga diperlukan sebuah rekomendasi perbaikan metode kerja aktivitas $\mathrm{MMH}$ agar mendominasi Upper Extremity Work-Related Musculoskeletal Disorders (UEWMSDs) (Oesman et al., 2019). Sedangkan berdasarkan analisis postur dengan 3DSSPP pengaruh terhadap kompresi L5/S1 dalam batas aman. Namun perbaikan pada postur dianggap penting karena aktivitas yang banyak menggunakan otot secara statis akan berdampak pada kelelahan otot lokal akibat banyaknya persentase otot yang berkontraksi sehingga durasi kekuatan otot akan semakin mengecil seiring aktivitas $\mathrm{MMH}$ terutama pada aktivitas membawa dengan gaya kompresi senilai $2580 \mathrm{~N}$ memiliki faktor penyebab risiko membahayakan pekerja / operator seperti low back pain (LBP). hal ini senada dengan (Suryadi \& Rachmawati, 2020) menyebutkan bahwa mengangkat beban lebih berat $>5 \mathrm{~kg}$ risiko 2,3 kali lebih besar mengalami low back pain dibandingkan mengangkat berat $<5 \mathrm{~kg}$. pada aktivitas pengangkatan beban akan berpengaruh pada tulang belakang pada bagian lumbar akibat terjadinya tekanan pada bagian L5/S1

Selain itu, aktivitas membawa beban akan ikut andil dalam risiko Work-Related Musculoskeletal Disorders (WMSDs) terhadap durasi dan jarak yang harus ditempuh pekerja/operator dalam melaksanakan tugasnya. Risikorisiko yang dapat menimbulkan permasalahan MSDs kerap kali berawal dari postur kerja pada aktivitas MMH yang tidak ergonomis sehingga mengakibatkan posisi tubuh yang tidak sesuai dan menjauhi dari pusat gravitasi (Nuryaningtyas \& Martiana, 2014).

\section{KESIMPULAN}

Berdasarkan hasil penilaian postur menggunakan RULA maka dapat disimpulkan bahwa aktivitas manual material handling galon air mineral pada gedung bertingkat merupakan aktivitas yang memiliki nilai 7 dan perlu dilakukan perbaikan. Salah satu penyebab penilaian postur kerja MMH menjadi risiko adalah penambahan pada nilai beban yang diangkut cukup berat yaitu $>10 \mathrm{Kg}$. Nilai faktor beban eksternal aktivitas kerja memperlihatkan nilai yang tinggi dan tidak bisa dihindari atau dikurangi karena kemasan galon air mineral merupakan produk jadi.

Usulan atau rekomendasi perbaikan dari analisis postur adalah dengan cara posisi tubuh dan leher agar pada posisi tegak, posisi tangan harus seimbang dengan sudut posisi yang sama, menggunakan alat bantu coupling yang sesuai serta alat bantu material handling untuk membawa galon agar berat dari galon tidak ditampung dengan kekuatan manusia seperti troli, atau alat bantu lifting baik secara mekanis atau elektrik. 


\section{SARAN}

Agar adanya penelitian dengan pendekatan dan metode penilaian postur khususnya penilaian biomekanika agar intervensi ergonomi pada aktivitas manual material handling lebih komprehensif. Dan diharapkan penelitian selanjutnya terkait perancangan peralatan bantu MMH aktivitas pada gedung bertingkat yang dapat disesuaikan dengan kebutuhan kerja serta memenuhi efektif, aman, sehat, nyaman dan efisien.

\section{DAFTAR PUSTAKA}

Affa, M. N., \& Putra, B. I. 2017 Analisis Manual Material Handling Pada Pekerja Borongan Di PT. JC dengan Metode NBM dan RWL. PROZIMA (Productivity, Optimization and Manufacturing System Engineering), $1(1), \quad 22$. https://doi.org/10.21070/prozima.v1i1.703

Afshari, D., Latifi, S. M., Kord, S., \& NourollahiDarabad, M. 2018. Assessment of low back disorders risk based on allowable weight limits for manual lifting in Iran. Industrial Health, 56(4), 327-335. https://doi.org/10.2486/indhealth.20170174

Bintang, A. N., \& Dewi, S. K. 2017. Analisa Postur Kerja Menggunakan Metode OWAS dan RULA. Jurnal Teknik Industri, 18(1), 43. https://doi.org/10.22219/jtiumm.vol18.no1.43-54

Namwongsa, S., Puntumetakul, R., Neubert, M. S., Chaiklieng, S., \& Boucaut, R. 2018. Ergonomic risk assessment of smartphone users using the Rapid Upper Limb Assessment (RULA) tool. PLoS ONE, 13(8), 1-16. https://doi.org/10.1371/journal.pone.0203394

Nuryaningtyas, B. M., \& Martiana, T. 2014. Analisis Tingkat Risiko Muskuloskeletal Disorders (Msds) Dengan The Rapid Upper Limbs Assessment (RULA) Dan Karakteristik Individu Terhadap Keluhan Msds. The Indonesian Journal of Occupational Safety and Health, 3(2), 160-169.

Oesman, T. I., Irawan, E., \& Wisnubroto, P. 2019. Analisis Postur Kerja dengan RULA Guna Penilaian Tingkat Risiko Upper Extremity WorkRelated Musculoskeletal Disorders. Studi Kasus PT. Mandiri Jogja Internasional. Jurnal Ergonomi Indonesia (The Indonesian Journal of Ergonomic), $5(1)$,

39. https://doi.org/10.24843/jei.2019.v05.i01.p06

Sanjaya, K. T., Wirawan, N. H., \& Adenan, B. 2018. Analisis Postur Kerja Manual Material Handling Menggunakan Biomekanika dan Niosh. JATI UNIK: Jurnal Ilmiah Teknik Dan Manajemen Industri, I(1),

61. https://doi.org/10.30737/jatiunik.v1i2.114

Sunedi, S., Imron, M., \& Purwangka, F. 2019. Penilaian
Postur Kerja dan Risiko Musculoskeletal Disorders pada Aktivitas Penangkapan Glass Eel. Jurnal Akuatika Indonesia, 4(2), 65-70.

Suryadi, I., \& Rachmawati, S. 2020. Work Posture Relations With Low Back Pain Complaint on Partners Part of Pt " $X$ " Manufacture of Tobacco Products. Journal of Vocational Health Studies, 3(3), https://doi.org/10.20473/jvhs.v3.i3.2020.126-130

Susihono, W. 2016. Analisis Postur Kerja Dengan Metode Rappid Upper Limb Assessment ( RULA ) Sebagai Dasar Rekomendasi Redesign Fasilitas Kerja. Journal Industrial Servicess, 1(2), 266-271. http://jurnal.untirta.ac.id/index.php/jiss/article/view $/ 1617$

Taofik, I. M., \& Mauluddin, Y. 2015. Evaluasi Ergonomi Menggunakan Metode Rula (Rapid Upper Limb Assessment) Untuk Mengidentifikasi Alat Bantu Pada Mesin Roasting Kopi. Kalibrasi, 13(1), 1-13. https://jurnal.sttgarut.ac.id/index.php/kalibrasi/artic le/view/204

Tiogana, V., \& Hartono, N. 2020. Analisis Postur Kerja dengan Menggunakan REBA dan RULA di PT X. Journal of Integrated System, 3(1), 9-25. https://doi.org/10.28932/jis.v3i1.2463

Wijaya, I. S. A., \& Muhsin, A. 2018. Analisa Postur Kerja Dengan Metode Rapid Upper Limb Assessment (RULA) Pada Operator Mesin Extruder Di Stasiun Kerja Extruding Pada Pt Xyz. Opsi, 11(1), 49. https://doi.org/10.31315/opsi.v11i1.2200

Zen, Z. H., \& Zamora, B. 2016. Analisis Postur Kerja Pada Bagian Gudang Barang Jadi Menggunakan Metoderapid Entire Body Assessment (REBA). Photon: Jurnal Sain Dan Kesehatan, 7(01), 113119. https://doi.org/10.37859/jp.v7i01.568 